\title{
Bidirectional predictions between Internet addiction and probable depression among Chinese adolescents
}

\author{
JOSEPH T. F. LAU ${ }^{1,2 *}$, DANIELLE L. WALDEN ${ }^{1}$, ANISE M. S. WU ${ }^{3}$, KIT-MAN CHENG ${ }^{1}$, \\ MASON C. M. LAU ${ }^{1}$ and PHOENIX K. H. MO ${ }^{1}$ \\ ${ }^{1}$ Centre for Health Behaviours Research, The Jockey Club School of Public Health and Primary Care, Faculty of Medicine, \\ The Chinese University of Hong Kong, Hong Kong, China \\ ${ }^{2}$ School of Public Health, Zhengjiang University, Hangzhou, China \\ ${ }^{3}$ Department of Psychology, Faculty of Social Sciences, University of Macau, Macao, China
}

(Received: November 1, 2017; revised manuscript received: November 23, 2017; second revised manuscript received: August 8, 2018; accepted: August 9, 2018)

\begin{abstract}
Background and aims: The aim of the study is to investigate (a) whether probable depression status assessed at baseline prospectively predicted new incidence of Internet addiction (IA) at the 12-month follow-up and (b) whether IA status assessed at baseline prospectively predicted new incidence of probable depression at follow-up. Methods: We conducted a 12-month cohort study $(n=8,286)$ among Hong Kong secondary students, and derived two subsamples. The first subsample $(n=6,954)$ included students who were non-IA at baseline, using the Chen Internet Addiction Scale $(\leq 63)$, and another included non-depressed cases at baseline $(n=3,589)$, using the Center for Epidemiological Studies Depression Scale $(<16)$. Results: In the first subsample, $11.5 \%$ of the non-IA cases developed IA during follow-up, and probable depression status at baseline significantly predicted new incidence of IA [severe depression: adjusted odds ratio $(\mathrm{ORa})=2.50,95 \% \mathrm{CI}=2.07,3.01$; moderate: $\mathrm{ORa}=1.82,95 \% \mathrm{CI}=1.45$, 2.28; mild: $\mathrm{ORa}=1.65,95 \% \mathrm{CI}=1.32,2.05$; reference: non-depressed], after adjusting for sociodemographic factors. In the second subsample, $38.9 \%$ of those non-depressed participants developed probable depression during follow-up. Adjusted analysis showed that baseline IA status also significantly predicted new incidence of probable depression $(\mathrm{ORa}=1.57,95 \% \mathrm{CI}=1.18,2.09)$. Discussion and conclusions: The high incidence of probable depression is a concern that warrants interventions, as depression has lasting harmful effects in adolescents. Baseline probable depression predicted IA at follow-up and vice versa, among those who were free from IA/probable depression at baseline. Healthcare workers, teachers, and parents need to be made aware of this bidirectional finding. Interventions, both IA and depression prevention, should thus take both problems into consideration.
\end{abstract}

Keywords: Internet addiction, depression, adolescents, Chinese, longitudinal study

\section{INTRODUCTION}

Internet addiction (IA) refers to generalized symptoms resulting from excessive online activities, including uncontrollable urges, preoccupation with use, and problems encountered when attempting to cut back, and poor school and job performance (Young, 2004). Although not recognized as a disorder in nosography manuals, it is associated with academic problems (Tang et al., 2014; Yang \& Tung, 2007), family problems (Park, Kim, \& Cho, 2008; Yang \& Tung, 2007), low self-esteem (Yang \& Tung, 2007), hopelessness, anxiety (Cho, Sung, Shin, Lim, \& Shin, 2013; Fu, Chan, Wong, \& Yip, 2010; Tang et al., 2014), depression (Cheung \& Wong, 2011; Cho et al., 2013; Fu et al., 2010; Tang et al., 2014; Yang \& Tung, 2007), and suicide ideation (Fu et al., 2010) among adolescents. However, the majority of these findings were based on cross-sectional studies.

Based on the Chen Internet Addiction Scale (CIAS; Chen, Weng, Su, Wu, \& Yang, 2003), the prevalence of adolescent IA was $9.6 \%$ in China, $16.4 \%$ in Hong Kong, $6.2 \%$ in Japan, $9.7 \%$ in South Korea, $14.1 \%$ in Malaysia, and $21.1 \%$ in the Philippines (Mak, Lai, Watanabe, et al., 2014). The relationship between IA and depression among adolescents is of particularly important as adolescent depression is prevalent and impactful. Depressive disorders ranked as the fourth leading cause of disability-adjusted lifeyears among the adolescents (Global Burden of Disease Pediatrics Collaboration et al., 2016). Adolescent depression caused depression in early adulthood (O'Connor et al., 2011), smoking, suicidal ideation, and suicide attempt (Lam et al., 2005; Lewinsohn, Rohde, \& Seeley, 1994; Wong et al., 2008). Based on a commonly used non-diagnostic

\footnotetext{
* Corresponding author: Joseph T. F. Lau; Faculty of Medicine, Centre for Health Behaviours Research, The Jockey Club School of Public Health and Primary Care, The Chinese University of Hong Kong, 5/F, Hong Kong, China; Phone: +852 2637 6606; Fax: +852 2645 3098; E-mail: jlau@cuhk.edu.hk
}

This is an open-access article distributed under the terms of the Creative Commons Attribution-NonCommercial 4.0 International License, which permits unrestricted use, distribution, and reproduction in any medium for non-commercial purposes, provided the original author and source are credited, a link to the CC License is provided, and changes - if any - are indicated. 
screening tool, the Center for Epidemiological Studies Depression Scale (CESD), a Taiwan study (Lin et al., 2008), a mainland China study (Jin, Chang, \& Ma, 2013), and a Hong Kong study (Li, Chan, Chung, \& Chui, 2010) reported prevalence of severe depression (CESD $>28$ ) of $12.3 \%$ and probable depression $(C E S D \geq 16)$ of $30.0 \%-38.3 \%$ among adolescents. Two studies that used other tools reported a prevalence of probable depression of 19.1\% (moderate-severe) (Lam, 2015) and 11.3\% (Chan, Leung, Fong, Leung, \& Lee, 2010) among Hong Kong adolescents.

In a systematic review, 14 studies reported significant associations between IA and depression (Carli et al., 2013). One longitudinal study $(n=1,041)$ conducted in Guangzhou, China found that severe/moderate pathological Internet use predicted adolescent incident depression during a 9-month follow-up period (Lam \& Peng, 2010); other longitudinal studies investigated the relationship between changes in levels of depression and IA symptoms (Dong, Lu, Zhou, \& Zhao, 2011; Fu et al., 2010). In the reverse direction, several studies conducted in Korea $(n=489$; Cho et al., 2013) and Taiwan $(n=1,602$ and 1,848; Chang, Chiu, Lee, Chen, \& Miao, 2014; Ko, Yen, Chen, Yeh, \& Yen, 2009) found that baseline depression prospectively predicted incident IA cases. Thus, the prospective relationship between IA and depression could be unidirectional or bidirectional. Only two studies investigated such bidirectional relationships in the same study. A 6-month longitudinal study $(n=660)$ conducted in the Netherlands found no significant prediction in either direction (van den Eijnden, Meerkerk, Vermulst, Spijkerman, \& Engels, 2008). A Spanish study found that only particular aspects of problematic Internet use predicted depression symptoms while depression symptoms predicted some aspects of problematic Internet use among adolescents (Gamez-Guadix, 2014).

As both IA and depression can be the causes and consequences of each other, this study provides better understandings than many existing cross-sectional studies on whether IA predicts incident depression, depression predicts incident IA, or both are true. To answer the question, we have to use subsamples within the same sample to eliminate sampling and methodological differences. The two similar studies (Gamez-Guadix, 2014; van den Eijnden et al., 2008) involved different methodologies, and did not focus on prediction of conversion of IA/depression status. No study has looked at bidirectional prediction of incident IA and probable depression among those who are free from such conditions at baseline within the same sample. This study made such attempts and contributions to literature. If there are significant predictions, the study has strong implications on prevention of IA among those without IA at baseline by suggesting that such interventions should reduce depressive symptoms among those who are probable depression cases at baseline. Similarly, depression prevention among nonprobable depression cases at baseline should include elements of reducing Internet overuse targeting those with IA at baseline.

In this longitudinal study, we used two validated scales (CESD and CIAS) and their cut-off points, which have strong literature support, to identify conversions of probable depression and IA statuses. The cut-off point of CESD $\geq 16$ was associated with depression defined by both standardized psychiatric interviews and assessment tools, suicide attempts, and unhealthy dietary/sleep patterns (Akbaraly et al., 2009; Jones et al., 2005; Radloff, 1977; Supartini, Oishi, \& Yagi, 2017; Weissman, Sholomskas, Pottenger, Prusoff, \& Locke, 1977; Yang, Jia, \& Qin, 2015). It predicted incidences of early hypertension and diabetes, and cardiovascular mortality (Davidson, Jonas, Dixon, \& Markovitz, 2000; Everson-Rose et al., 2004; Tillmann et al., 2017). One study reported satisfactory test-retest reliability and dimensionality, and found that about half of Grade 9-12 students were probable depression cases $(\geq 16)$ (Roberts, Andrews, Lewinsohn, \& Hops, 1990). Studies also used CESD $\geq 16$ to estimate probable depression prevalence among Chinese adolescents (e.g., Ding et al., 2017; Jin et al., 2013; Liu, Hong, \& Niu, 2012; Yang et al., 2015). Such studies also found significant relationships between probable depression $(\mathrm{CESD} \geq 16)$ and health problems, such as substance dependence (Dai, Xiu, Li, Wang, \& Hu, 2017), suicidal attempts (Yang et al., 2015), and childhood trauma (Ding et al., 2017) among Chinese adolescents.

The validity of the CIAS was confirmed by testing against the diagnostic results formulated by some psychiatrists among 454 Chinese adolescents, and the cut-off point $(63 / 64)$ was the best for discriminating IA cases from noncases, with a high accuracy $(87.6 \%)$ and specificity $(92.6 \%)$ (Ko et al., 2005). This cut-off point has been employed in other Chinese adolescent studies (e.g., Ko et al., 2015; Mak, Lai, Ko, et al., 2014; Yen, Ko, Yen, Chang, \& Cheng, 2009; Yen, Yen, Chen, Chen, \& Ko, 2007). The classification outcome was significantly associated with daily Internet use, Internet use $>20 \mathrm{hr} /$ week, and online gaming. It was also associated with numerous psychosocial problems, such as aggression, neuroticism, poor overall family function, high parent-adolescent conflict, substance-use experience, poor mental health, and poor social functioning (Ko et al., 2005, 2006; Ko, Yen, Liu, Huang, \& Yen, 2009; Mak, Lai, Watanabe, et al., 2014; Yan, Li, \& Sui, 2014; Yen et al., 2007).

We investigated whether the status of probable depression assessed at baseline would prospectively predict incident IA during the 12-month follow-up among those who were free from IA at baseline, and whether IA status assessed at baseline would predict incident probable depression developed during the follow-up period among those who were free from probable depression at baseline. We hypothesized that (a) IA at baseline would predict conversion from non-probable depression at baseline to probable depression at follow-up among those who were nondepressed at baseline, and (b) probable depression at baseline would predict the conversion from non-IA at baseline to IA at follow-up among those who were non-IA at baseline.

\section{METHODS}

\section{Participants and procedures}

The baseline survey was conducted during September 2012 through January 2013. We invited all Chinese Secondary 1-4 students of one school from each of the 19 districts in 
Hong Kong to participate in the study. Parents could return an opt-out form (1.6\%). The return of the completed anonymous questionnaire implied informed consent. A total of 9,666 students voluntarily participated in the baseline survey (response rate $=94.1 \%$ ) in classroom settings. The follow-up survey was conducted during September 2013 through February 2014. Participants' identity card number (last five digits), date of birth, and phone number (last four digits) were used for matching. Using the same data set, some sociodemographic and cognitive predictors of incident IA (not included depression) were reported in another paper (Lau, Gross, Wu, Cheng, \& Lau, 2017).

\section{Measures}

IA status. IA status was assessed using the 26-item CIAS. Ko et al. (2005) have validated CIAS among Chinese adolescents and suggested the cut-off score of CIAS $>63$ for defining IA cases. Items were measured on Likert scales ranging from 1 (does not apply to me at all) to 4 (applies to me very much), and total score ranged from 26 to 104. Cronbach's $\alpha$ was .95 at both baseline and follow-up.

Probable depression. Depressive symptoms in the preceding week were assessed using CESD-20, which was translated into Chinese and had shown good internal consistency among Hong Kong adolescents (Li et al., 2010). The items were rated on 4-point Likert scales, ranging from 0 (never) to 3 (often). The cut-off point of $\geq 16$ defined probable depression (mild-severe). Probable depression represents higher risk of having depression instead of a clinical diagnostic status. Cronbach's $\alpha$ values were .90 and .91 at baseline and follow-up, respectively.

Background variables. Sociodemographic data were recorded.

\section{Statistical analyses}

$\chi^{2}$ tests and independent-sample $t$-tests were performed for between-group comparisons. Multilevel logistic regression models (MLwiN 2.30; developed by Centre for Multilevel Modelling, University of Bristol, UK) were fit to investigate longitudinal predictions, considering intracorrelation among participants. Two-level models (Level 1: student; Level 2: school) with random intercepts were fit, allowing intercepts of the regression models to vary across schools. Separate categories were created for missing responses. We adjusted for sociodemographics, and also baseline CIAS (or CESD) when predicting incident IA (or probable depression) at the follow-up. SPSS version 20.0.0 was used for other data analysis. Statistical significance was claimed at $p<.05$.

\section{Ethics}

Informed consent was sought from both the student participants and their parents. The questionnaire was anonymous, and the baseline and follow-up data were matched by a self-generated code based on the last five digits of each participant's identity card, their date of birth, and the last four digits of their phone number. The study procedures were carried out in accordance with the Declaration of Helsinki. Ethical approval was obtained from the Survey and Behavioral Ethics Committee, the Chinese University of Hong Kong.

\section{RESULTS}

\section{The two subsamples}

Of the 10,275 students invited, 9,666 (94.1\%) and 9,762 (95.0\%) completed the baseline and 12-month follow-up surveys, respectively; $8,286(85.7 \%)$ could be matched. The first subsample consisted of those who were free from IA (CIAS $\leq 63$ ) at baseline (the non-IA subsample; $n=6,954$ ), and was used for the prediction of incident IA cases at follow-up, using the baseline CESD score. The second one consisted of those who did not have probable depression $(\mathrm{CESD}<16)$ at baseline (the non-depressed subsample; $n=$ 3,589 ), and was used for prediction of incident probable depression cases at follow-up, using the baseline IA status. Of the participants of the entire sample $(n=8,286), 40.5 \%$ belonged to both subsamples.

\section{Participants' baseline characteristics}

In the non-IA subsample, those who were loss-to-follow-up were more likely than the followed-up group to be males and Secondary 4 school students, have a parent with higher education, live with only one parent or no parent, and have moderate to severe depression $(p<.05)$; similar differences were observed in the non-depressed subsample (Table 1). Some of these comparisons were previously reported (Lau et al., 2017).

In the non-IA subsample $(n=6,954), 51.0 \%$ were male, $16.1 \% / 12.8 \%$ had a father/mother with university education or above, respectively, $84.2 \%$ lived with both parents, and $78.9 \%$ were born in Hong Kong. Their prevalence of probable mild to severe depression $(\mathrm{CESD} \geq 16)$ at baseline was $51.1 \%(16.0 \%, 13.7 \%$, and $21.4 \%$ for mild, moderate, and severe depression, respectively). The background characteristics of the followed-up non-depressed subsample $(n=3,589)$ were similar to those of the first subsample (Table 1). The prevalence of IA (CIAS >63) at baseline was $6.2 \%$ in this non-depressed subsample.

\section{Sociodemographic factors as predictors}

In the non-IA subsample, female sex negatively predicted [univariate odds ratio $(\mathrm{ORu})=0.71,95 \% \mathrm{CI}=0.61,0.83$ ], while birthplace outside Hong Kong and absence of information about the length of stay in Hong Kong positively predicted $(\mathrm{ORu}=1.64,95 \% \mathrm{CI}=1.03,2.61)$ incident IA. Female sex positively predicted $(\mathrm{ORu}=1.27,95 \% \mathrm{CI}=1.10$, 1.47), while birthplace outside Hong Kong but having lived in Hong Kong for $<7$ years negatively predicted $(\mathrm{ORu}=$ $0.73,95 \% \mathrm{CI}=0.56,0.96)$ incident probable depression.

\section{Using baseline probable depression/IA status to predict incident IA/probable depression}

In the non-IA subsample, 797 (11.5\%) turned into incident IA cases during the follow-up period. Adjusted for all 
Table 1. Comparison of baseline characteristics between followed up cases and loss-to-follow-up cases among participants of the two subsamples

\begin{tabular}{|c|c|c|c|c|}
\hline & \multicolumn{4}{|c|}{ Column \%/Mean $(S D)$} \\
\hline & \multicolumn{2}{|c|}{$\begin{array}{c}\text { Non-probable IA }(\text { CIAS } \leq 63) \text { at } \\
\text { baseline }(N=8,073)\end{array}$} & \multicolumn{2}{|c|}{$\begin{array}{c}\text { Non-probable depression }(\mathrm{CESD}<16) \\
\text { at baseline }(N=4,100)\end{array}$} \\
\hline & $\begin{array}{l}\text { Followed up }(n=6,954 ; \\
\text { i.e., non-IA subsample })\end{array}$ & $\begin{array}{l}\text { Loss-to-follow-up } \\
\quad(n=1,119)\end{array}$ & $\begin{array}{l}\text { Followed up }(n=3,589 ; \\
\text { i.e., } \text { non-depressed } \\
\text { subsample })\end{array}$ & $\begin{array}{l}\text { Loss-to-follow-up } \\
\quad(n=511)\end{array}$ \\
\hline \multicolumn{5}{|l|}{$\mathrm{Sex}^{\mathrm{a}, \mathrm{b}}$} \\
\hline Male & 51.0 & 61.1 & 57.1 & 69.3 \\
\hline Female & 48.5 & 37.9 & 42.3 & 29.9 \\
\hline Missing & 0.5 & 1.0 & 0.5 & 0.8 \\
\hline \multicolumn{5}{|l|}{ School grade ${ }^{\mathrm{a}, \mathrm{b}}$} \\
\hline Secondary 1 & 25.5 & 26.2 & 28.5 & 29.4 \\
\hline Secondary 2 & 25.0 & 21.3 & 26.1 & 22.5 \\
\hline Secondary 3 & 25.9 & 25.6 & 24.4 & 21.7 \\
\hline Secondary 4 & 23.7 & 26.9 & 21.0 & 26.4 \\
\hline \multicolumn{5}{|l|}{ Father's education level ${ }^{\mathrm{a}, \mathrm{b}}$} \\
\hline Junior secondary or below & 27.7 & 21.9 & 26.7 & 20.7 \\
\hline Senior secondary & 38.9 & 33.8 & 38.7 & 34.6 \\
\hline University/colleges or above & 16.1 & 25.9 & 17.0 & 27.8 \\
\hline Did not know & 17.4 & 18.4 & 17.6 & 16.8 \\
\hline \multicolumn{5}{|l|}{ Mother's education level ${ }^{\mathrm{a}, \mathrm{b}}$} \\
\hline Junior secondary or below & 28.1 & 22.6 & 27.7 & 20.4 \\
\hline Senior secondary & 42.8 & 37.1 & 41.3 & 39.3 \\
\hline University/colleges or above & 12.8 & 22.3 & 14.2 & 24.3 \\
\hline Did not know & 16.3 & 18.1 & 16.7 & 16.0 \\
\hline \multicolumn{5}{|l|}{ Living arrangement with parents ${ }^{\mathrm{a}}$} \\
\hline Living with both parents & 84.2 & 81.3 & 85.6 & 84.0 \\
\hline Not living with both parents & 2.8 & 3.2 & 2.3 & 2.5 \\
\hline Living only with mother & 8.9 & 9.6 & 8.3 & 7.6 \\
\hline Living only with father & 2.4 & 3.9 & 2.2 & 3.7 \\
\hline Missing & 1.7 & 2.0 & 1.6 & 2.2 \\
\hline \multicolumn{5}{|l|}{ Place of birth ${ }^{\mathrm{a}}$} \\
\hline Born in $\mathrm{HK}$ & 78.9 & 79.8 & 78.8 & 80.2 \\
\hline $\begin{array}{l}\text { Not born in } \mathrm{HK} \text { but had lived } \\
\text { in } \mathrm{HK} \geq 7 \text { years }\end{array}$ & 12.2 & 11.8 & 12.1 & 12.1 \\
\hline $\begin{array}{l}\text { Not born in HK but had lived } \\
\text { in } \mathrm{HK}<7 \text { years }\end{array}$ & 6.6 & 4.9 & 7.1 & 4.5 \\
\hline $\begin{array}{l}\text { Not born in HK and did not } \\
\text { remember how long he/she } \\
\text { had lived in HK }\end{array}$ & 1.8 & 2.2 & 1.5 & 2.2 \\
\hline Missing & 0.5 & 1.3 & 0.5 & 1.0 \\
\hline CIAS (range: 26-104) & $45.65(11.19)$ & $45.24(11.76)$ & $44.03(12.80)$ & $43.50(13.56)$ \\
\hline \multicolumn{5}{|l|}{ Classified as probable IA } \\
\hline No $($ CIAS $\leq 63)$ & 100.0 & 100.0 & 93.6 & 94.1 \\
\hline Yes (CIAS > 63) & 0.0 & 0.0 & 6.2 & 5.3 \\
\hline Missing & 0.0 & 0.0 & 0.2 & 0.6 \\
\hline CESD (range: $0-60)^{\mathrm{a}, \mathrm{b}}$ & $16.97(9.95)$ & $18.78(10.48)$ & $8.75(4.01)$ & $9.36(3.86)$ \\
\hline \multicolumn{5}{|l|}{ Classified as probable depression ${ }^{\mathrm{a}}$} \\
\hline No $(\mathrm{CESD}<16)$ & 48.3 & 43.0 & 100.0 & 100.0 \\
\hline Yes $($ CESD $\geq 16)$ & 51.1 & 55.8 & 0.0 & 0.0 \\
\hline Missing & 0.6 & 1.3 & 0.0 & 0.0 \\
\hline
\end{tabular}

Note. SD: standard deviation; HK: Hong Kong; IA: Internet addiction; CESD: Center for Epidemiological Studies Depression Scale; CIAS: Chen Internet Addiction Scale.

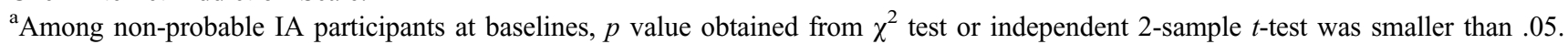

${ }^{\mathrm{b}}$ Among non-probable depressed participants at baselines, $p$ value obtained from $\chi^{2}$ test or independent 2-sample $t$-test was smaller than .05. 
sociodemographic background variables, baseline probable depression status significantly predicted incident IA [severe depression: adjusted odds ratio $(\mathrm{ORa})=2.50$; $95 \% \mathrm{CI}=2.07,3.01$; moderate depression: $\mathrm{ORa}=1.82$; $95 \% \mathrm{CI}=1.45,2.28$; mild depression: $\mathrm{ORa}=1.65 ; 95 \%$ $\mathrm{CI}=1.32,2.05$; reference $=$ not depressed at baseline $]$. The odds ratios remained statistically significant although became smaller when we further adjusted for baseline CIAS score (severe depression: $\mathrm{ORa}=1.74,95 \% \mathrm{CI}=1.43,2.11$; moderate depression: $\mathrm{ORa}=1.32,95 \% \mathrm{CI}=1.05,1.67$; mild depression: $\mathrm{ORa}=1.27,95 \% \mathrm{CI}=1.02,1.60$; reference $=$ not depressed; Table 2).

In the non-depressed subsample, 1,397 (38.9\%) turned into incident depression cases during follow-up. Similarly, adjusted for all background variables, baseline IA status significantly predicted incident probable mild or above depression $\quad(\mathrm{CESD} \geq 16) \quad(\mathrm{ORa}=1.57,95 \% \quad \mathrm{CI}=1.18$, 2.09) during follow-up. The odds ratios remained statistically significant when we further adjusted for the baseline $\mathrm{CESD}$ score $(\mathrm{ORa}=1.39,95 \% \mathrm{CI}=1.05,1.86$; Table 2).

\section{DISCUSSION}

In the non-IA subsample, $11.5 \%$ converted to IA. Incident IA was predicted by baseline probable depression status (adjusted analysis), with the odds ratios increasing with the severity of baseline probable depression status. The findings corroborated some Korean and Taiwanese adolescent studies (Chang et al., 2014; Cho et al., 2013; Ko, Yen, Chen, et al., 2009). Adolescents may develop IA when they seek excitement or escape from negative emotions through the Internet (Kardefelt-Winther, 2014; Kim \& Haridakis, 2009; Li, Liau, \& Khoo, 2011; Ryan, Chester, Reece, \& Xenos, 2014). Those with depressive symptoms are thus prone to develop problematic Internet use. It is plausible that those with baseline probable depression might have higher baseline CIAS scores (a potential confounder) that might also predict incident IA at follow-up. We have removed such effect, as the analysis was adjusted for baseline CIAS scores. The odds ratios remained significant and became smaller. It was substantial between those with severe probable depression and those without probable depression (the reference group) at baseline. Those with moderate/mild baseline probable depression only showed slightly moderate, but statistically significant, elevated risks for incident IA compared to the reference group (ORa about 1.3). A dosage effect was detected.

Baseline IA status also significantly predicted incident probable depression among those who were free from probable depression at baseline. Similar findings have been reported among adolescents in Guangzhou, China (Lam \& Peng, 2010). Adolescents with IA were vulnerable to adverse consequences such as low academic esteem and conflicts with/rejection by parents, and experienced high associated stress (Chen \& Peng, 2008; Li, Garland, \& Howard, 2014). These negative experiences and emotions (stressors) may induce depression (Hammen, 2005).

IA is a generalized problem that involves an umbrella of overlapping behaviors, as Internet use serves multiple purposes (e.g., information seeking, work, learning, leisure, and social interactions). Recently, specific Internet-related addictions (e.g., social networking addiction and Internet gaming disorder; Montag et al., 2015; Wu, Chen, Tong, Yu, $\&$ Lau, 2018) have drawn much attention. IA was significantly associated with such Internet-related addictions, but the strength of such associations and the associated factors depended on the exact type of addiction (Choi et al., 2015; Montag et al., 2015). It is a limitation of this study that we did not record specific Internet-related activities and did not assess specific forms of online addictive activities (e.g., Internet gaming disorder). Hence, we are unable to know which aspects of Internet use caused the participants' IA (Starcevic, 2013), and whether the observed bidirectional relationships would remain true for specific

Table 2. Baseline probable depression status and baseline IA status as predictors

\begin{tabular}{lc}
\hline & ORa $[95 \% \mathrm{CI}]^{\mathrm{a}}$ \\
\hline Prediction of new IA incidence among non-IA at baseline $(n=6,954)$ & 1 \\
Center for Epidemiologic Studies Depression (CESD) & $1.27[1.02,1.60]^{*}$ \\
$\quad$ Non-depressed (CESD $<16)$ & $1.32[1.05,1.67]^{*}$ \\
Mild depression (CESD $=16-20)$ & $1.74[1.43,2.11]^{* *}$ \\
Moderate depression (CESD $=21-24)$ & $1.43[0.54,3.82]$ \\
Severe depression (CESD $\geq 25)$ & 1 \\
Missing & $1.39[1.05,1.86]^{*}$ \\
Prediction of new probable depression incidence among non-depressed at baseline $(n=3,589)$ & 1.39 \\
Classified as Internet addict & \\
No (CIAS $\leq 63)$ & \\
Yes (CIAS $>63)$ &
\end{tabular}

Note. CI: confidence interval; IA: Internet addiction; CIAS: Chen Internet Addiction Scale; ORa: adjusted odds ratio.

${ }^{a}$ Odds ratio obtained by multilevel logistics regression (Level 1: student; Level 2: school) adjusted by all sociodemographic factors and either baseline CESD score (when predicting new IA incidence) or baseline CIAS score (when predicting new probable depression incidence), with varying-intercept across schools.

${ }^{*} p<.01 .{ }^{* *} p<.001$. 
Internet-related addictions. Such comparisons are warranted in future studies.

The observed prevalence of probable depression (mildsevere; CESD score $\geq 16$ ) was very high. Readers should be mindful about its interpretation. First, it is always true that prevalence of screening tools' results is tool-dependent and involves false positives, although the study used validated tools. Second, this study assessed probable depression (i.e., high risk of having depression instead of clinical diagnosis), which has higher prevalence than diagnosis. Third, false positives are more likely to occur when the disorder is rare (Maraz, Király, \& Demetrovics, 2015). Fourth, although various adolescent studies have found satisfactory reliability and validity of CESD, and many of them (including Chinese students) have used the same cutoff points and some have reported similarly high prevalence of probable depression (e.g., Jin et al., 2013; Radloff, 1991; Roberts et al., 1990), other cut-off points might have been chosen. A number of adult studies have reported satisfactory sensitivity and specificity regarding the CESD cut-off point of 16 (Cheung, Liu, \& Yip, 2007; Li \& Hicks, 2010; Stahl et al., 2008). It is a limitation that there are few such studies that involved adolescents. One study looked at sensitivity/ specificity of CESD $\geq 16$ regarding suicidal ideation among Irish youths 18-24 years old (Horgan, Kelly, Goodwin, \& Behan, 2018). Further studies need to look at the performance of different cut-off points of CESD, when it is applied to adolescents. Future studies may also compare the validity and cut-off points of CESD against those of Center for Epidemiologic Studies Depression Scale for Children (Weissman, Orvaschel, \& Padian, 1980), a version that has wording adjusted for children.

The high prevalence of probable depression is still worthy of attention. Previous local studies based on the same and different tools and cut-off points have reported high prevalence of probable depression in Hong Kong (Chan et al., 2010). It is possible that secondary students in Hong Kong are under huge stress (Leung \& To, 2009), which may increase the risk of depression. Same might be true in some Asian countries such as Vietnam (Nguyen, Dedding, Pham, \& Bunders, 2013). It is also alarming that about $40 \%$ of the non-depressed secondary students at baseline turned into probable depression cases during follow-up. Future studies on incidence of depression and prevention interventions are greatly warranted.

This may be the first study to test bidirectional predictions of incident IA/depression among those who were free from IA/depression at baseline from two subsamples of the same parent sample. Unlike this study, the two previous ones conducted in Spain and the Netherlands (GamezGuadix, 2014; van den Eijnden et al., 2008) did not find clear significant bidirectional relationships between adolescent IA and depression. These studies tested the associations between the symptoms (instead of conversions into problematic statuses) of these two health problems assessed at the baseline and follow-up, using cross-lagged analyses. The different findings between theirs and ours might be due to methodological differences (e.g., sampling, sample size, and length of follow-up) and contextual factors (e.g., education experience, culture, and availability of Internet). They treated IA and depression as continuous variables and used the entire sample; this study looked at conversion of status across cut-off points at follow-up in two subsamples that were initially free from the respective conditions. Both approaches have their merits and demerits.

Our "cut-off" approach has been very widely used to identify predictors of conversion into incident depression/IA over time among those were initially free from such conditions (e.g., Chang et al., 2014; Ko et al., 2015; Lam \& Peng, 2010; Rierdan, Koff, \& Stubbs, 1989; Suh et al., 2013). The tools and respective cut-off points used in this study have been well validated and widely applied to previous adolescent studies (Chang et al., 2014; Jin et al., 2013; Ko et al., 2005; Mak, Lai, Ko, et al., 2014; Radloff, 1991; Rodrigo et al., 2010; Schoenbach, Kaplan, Wagner, Grimson, \& Miller, 1983; Tamura, Nishida, Tsuji, \& Sakakibara, 2017; Yang et al., 2015). International comparisons are possible. The findings may be more interpretable than those based on continuous variables and regression coefficients and have better public health implications. The findings also inform design of selective interventions for prevention of incident IA/depression to consider both problems. The screening can be used to recruit participants for such interventions. One key limitation of our approach is, however, that those within the two dichotomized groups were regarded as having the same risk levels, an issue shared by all similar studies using this approach. From another angle, the cross-lagged approach has the advantage of utilizing the entire sample. It has also been commonly used, and can be used to identify the "causal winner." However, such comparison is not the purpose of the study. That approach also has the limitation that the practical meaning of a unit increase in scale score would differ according to the baseline scores. Thus, the two approaches actually answer different research questions and target different groups; both are potentially important depending on the purpose of the study. We believe that the "cut-off" approach was more adapted to our objectives.

Besides clarifying the significance of bidirectional prospective predictions, the findings have further important prevention implications. Prevention interventions for depression targeting students without probable depression at baseline are warranted, as $38.9 \%$ of them turned into probable depression cases $(C E S D \geq 16)$ after 1 year, according to our data. Our findings further suggest that among $6.2 \%$ of the students were IA cases at baseline, and more importantly, IA was a significant predictor of the conversion into incident depression. Using screening tests, healthcare workers can conduct selective interventions for students who are identified as not being probable depression cases (e.g., using CESD) but possess some high-risk factors of depression (e.g., low social support, loneliness, and low self-efficacy; Brage, Campbell-Grossman, \& Dunkel, 1995; Ehrenberg, Cox, \& Koopman, 1991; Lam \& Peng, 2010; Sheeber, Hops, Alpert, Davis, \& Andrews, 1997). Such interventions may be school-based and should include a special module of intervention for reducing Internet (e.g., self-control, time management, and outcome expectancy modification; Vondráčková \& Gabrhelík, 2016) for those with IA at baseline.

Similarly, IA prevention among non-IA students is also necessary, as $11.5 \%$ of them became IA cases after 
12 months. Of these target students (non-IA at baseline), $51.1 \%$ had probable depression at baseline and elevated risk of conversion to incident IA cases after 12 months. IA prevention targeting non-IA at baseline, therefore, may be beneficial by including a simple screening test for probable depression, and providing interventions among those with probable depression at baseline to reduce depressive symptoms (e.g., positive psychology intervention; Sin \& Lyubomirsky, 2009). A number of effective preventive interventions for IA have been reported (King et al., 2018). Prevention of both incident IA and incident depression may share some common risk factors (e.g., low self-esteem and poor family function; Lin et al., 2008; Yang \& Tung, 2007). Prevention interventions for IA/depression are different from treatment interventions, which attempt to reduce depressive symptoms and/or Internet overuse among those with probable depression and/or IA cases at baseline.

The study has some limitations. We believe that the findings can be generalized to Hong Kong, as we sampled schools from all of the districts and involved all students within the grades with a high response rate. Yet, school selection was not random. There was about $20 \%$ of loss-to-follow up. With the large sample size, many variables were statistically significant when the follow-up and non-follow-up cases were compared. Generalization to adult samples is unknown. Another limitation is that we recorded the grade but not age; age was relatively homogeneous with school grades in Hong Kong, but there are exceptions. The questions on IA may involve underreporting due to social desirability bias, whereas depressed people may overreport IA symptoms because of their negative perceptions and evaluations of themselves and their behaviors (Baggio et al., 2015). Last but not least, given practical constraints and resource limitations, there were only two surveys conducted 1 year apart. A longer-term follow-up is warranted. The test-retest reliability is another potential issue. It is a limitation that it was not tested in this study, although previous studies reported satisfactory to good 1-week testretest reliability for CESD among adolescents (Roberts et al., 1990; Yang, Soong, Kuo, Chang, \& Chen, 2004).

\section{CONCLUSIONS}

Our findings demonstrate that IA potentially predicted probable depression and vice versa for those who were free from the predicted outcome at the baseline. Although we find significant bidirectional predictions, the research design cannot establish causalities. Besides the effect of baseline depressive symptoms on IA at follow-up, depressive symptoms at follow-up, or symptoms developed during the two time points, may also affect IA at follow-up; IA level at follow-up may similarly affect depression at follow-up. Our data support the hypothesis that IA and depression symptoms are potential causes and consequences of each other. The contention about causalities requires further longitudinal studies. However, practical skills for promoting controlled Internet use should be incorporated in programs targeting adolescents who show depressive symptoms and signs of IA. IA prevention programs should also reduce negative moods of those with depressive symptoms. Related health workers thus need to develop new awareness and skill sets. Pilot intervention research and programs that simultaneously tackle both IA and depression problems are warranted.

Funding sources: This study was supported by the Health and Medical Research Fund (award number: 09100591).

Authors' contribution: JTFL was the principal investigator of the project. He designed the proposal, study, and questionnaire. He was responsible for the entire project, monitored the progress of the project, and prepared and finalized the manuscript. DLWG and AMSW conducted literature searches, interpreted the findings, and prepared the manuscript. K-MC was involved in data analysis. MCML participated in coordination and implementation of the project as well as data analysis. PKHM was involved in questionnaire design and result interpretation. All authors contributed to and approved the final version of the manuscript.

Conflict of interest: The authors declare no conflict of interest.

\section{REFERENCES}

Akbaraly, T. N., Brunner, E. J., Ferrie, J. E., Marmot, M. G., Kivimaki, M., \& Singh-Manoux, A. (2009). Dietary pattern and depressive symptoms in middle age. The British Journal of Psychiatry, 195(5), 408-413. doi:10.1192/bjp.bp.108.058925

Baggio, S., Iglesias, K., Studer, J., Dupuis, M., Daeppen, J. B., \& Gmel, G. (2015). Is the relationship between major depressive disorder and self-reported alcohol use disorder an artificial one? Alcohol and Alcoholism, 50(2), 195-199. doi:10.1093/ alcalc/agu103

Brage, D., Campbell-Grossman, C., \& Dunkel, J. (1995). Psychological correlates of adolescent depression. Journal of Child and Adolescent Psychiatric Nursing, 8(4), 23-30. doi:10.1111/ j.1744-6171.1995.tb00547.x

Carli, V., Durkee, T., Wasserman, D., Hadlaczky, G., Despalins, R., Kramarz, E., Wasserman, C., Sarchiapone, M., Hoven, C. W., Brunner, R., \& Kaess, M. (2013). The association between pathological Internet use and comorbid psychopathology: A systematic review. Psychopathology, 46(1), 1-13. doi: 10.1159/000337971

Chan, Y. F., Leung, D. Y., Fong, D. Y., Leung, C. M., \& Lee, A. M. (2010). Psychometric evaluation of the Hospital Anxiety and Depression Scale in a large community sample of adolescents in Hong Kong. Quality of Life Research, 19(6), 865-873. doi:10.1007/s11136-010-9645-1

Chang, F. C., Chiu, C. H., Lee, C. M., Chen, P. H., \& Miao, N. F. (2014). Predictors of the initiation and persistence of Internet addiction among adolescents in Taiwan. Addictive Behaviors, 39(10), 1434-1440. doi:10.1016/j.addbeh.2014.05.010

Chen, Y. F., \& Peng, S. S. (2008). University students' Internet use and its relationships with academic performance, interpersonal relationships, psychosocial adjustment, and self-evaluation. CyberPsychology \& Behavior, 11(4), 467-469. doi:10.1089/ cpb.2007.0128 
Chen, S. H., Weng, L. J., Su, Y. J., Wu, H. M., \& Yang, P. F. (2003). Development of a Chinese Internet Addiction Scale and its psychometric study. Chinese Journal of Psychology, 45(3), 279-279. doi:10.1037/t44491-000

Cheung, L. M., \& Wong, W. S. (2011). The effects of insomnia and Internet addiction on depression in Hong Kong Chinese adolescents: An exploratory cross-sectional analysis. Journal of Sleep Research, 20(2), 311-317. doi:10.1111/j.1365-2869. 2010.00883.x

Cheung, Y. B., Liu, K. Y., \& Yip, P. S. (2007). Performance of the CES-D and its short forms in screening suicidality and hopelessness in the community. Suicide and Life-Threatening Behavior, 37(1), 79-88. doi:10.1521/suli.2007.37.1.79

Cho, S. M., Sung, M. J., Shin, K. M., Lim, K. Y., \& Shin, Y. M. (2013). Does psychopathology in childhood predict Internet addiction in male adolescents? Child Psychiatry and Human Development, 44(4), 549-555. doi:10.1007/s10578012-0348-4

Choi, S. W., Kim, D. J., Choi, J. S., Ahn, H., Choi, E. J., Song, W. Y., Kim, S., \& Youn, H. (2015). Comparison of risk and protective factors associated with smartphone addiction and Internet addiction. Journal of Behavioral Addictions, 4(4), 308-314. doi:10.1556/2006.4.2015.043

Dai, B., Xiu, C., Li, X., Wang, Z., \& Hu, Y. (2017). Risk behavior characteristics of adolescents and youth abusing recreational drugs and associated factors of their depression status. Chinese Journal of AIDS and STD, 23(8), 742-744. doi:10.13419/j.cnki.aids.2017.08.18

Davidson, K., Jonas, B. S., Dixon, K. E., \& Markovitz, J. H. (2000). Do depression symptoms predict early hypertension incidence in young adults in the CARDIA study? Archives of Internal Medicine, 160(10), 1495-1500. doi:10.1001/archinte. 160.10.1495

Ding, H., Han, J., Zhang, M., Wang, Y., Lei, M., Wang, K., Yang, S., \& Yu, X. (2017). Relationship among childhood trauma resilience and depressive symptom in adolescents. Chinese Mental Health Journal, 31, 798-802. doi:10.3969/j. issn.1000-6729.2017.10.009

Dong, G., Lu, Q., Zhou, H., \& Zhao, X. (2011). Precursor or sequela: Pathological disorders in people with Internet addiction disorder. PLoS One, 6(2), e14703. doi:10.1371/journal. pone. 0014703

Ehrenberg, M. F., Cox, D. N., \& Koopman, R. F. (1991). The relationship between self-efficacy and depression in adolescents. Adolescence, 26(102), 361-374.

Everson-Rose, S. A., Meyer, P. M., Powell, L. H., Pandey, D., Torréns, J. I., Kravitz, H. M., Bromberger, J. T., \& Matthews, K. A. (2004). Depressive symptoms, insulin resistance, and risk of diabetes in women at midlife. Diabetes Care, 27(12), 2856-2862. doi:10.2337/diacare.27.12.2856

Fu, K. W., Chan, W. S., Wong, P. W., \& Yip, P. S. (2010). Internet addiction: Prevalence, discriminant validity and correlates among adolescents in Hong Kong. British Journal of Psychiatry, 196(6), 486-492. doi:10.1192/bjp.bp.109.075002

Gamez-Guadix, M. (2014). Depressive symptoms and problematic Internet use among adolescents: Analysis of the longitudinal relationships from the cognitive-behavioral model. Cyberpsychology, Behavior and Social Networking, 17(11), 714-719. doi:10.1089/cyber.2014.0226

Global Burden of Disease Pediatrics Collaboration, Kyu, H. H., Pinho, C., Wagner, J. A., Brown, J. C., Bertozzi-Villa, A.,
Charlson, F. J., Coffeng, L. E., Dandona, L., Erskine, H. E., Ferrari, A. J., Fitzmaurice, C., Fleming, T. D., Forouzanfar, M. H., Graetz, N., Guinovart, C., Haagsma, J., Higashi, H., Kassebaum, N. J., Larson, H. J., Lim, S. S., Mokdad, A. H., Moradi-Lakeh, M., Odell, S. V., Roth, G. A., Serina, P. T., Stanaway, J. D., Misganaw, A., Whiteford, H. A., Wolock, T. M., Wulf Hanson, S., Abd-Allah, F., Abera, S. F., AbuRaddad, L. J., AlBuhairan, F. S., Amare, A. T., Antonio, C. A., Artaman, A., Barker-Collo, S. L., Barrero, L. H., Benjet, C., Bensenor, I. M., Bhutta, Z. A., Bikbov, B., Brazinova, A., Campos-Nonato, I., Castañeda-Orjuela, C. A., Catalá-López, F., Chowdhury, R., Cooper, C., Crump, J. A., Dandona, R., Degenhardt, L., Dellavalle, R. P., Dharmaratne, S. D., Faraon, E. J., Feigin, V. L., Fürst, T., Geleijnse, J. M., Gessner, B. D., Gibney, K. B., Goto, A., Gunnell, D., Hankey, G. J., Hay, R. J., Hornberger, J. C., Hosgood, H. D., Hu, G., Jacobsen, K. H., Jayaraman, S. P., Jeemon, P., Jonas, J. B., Karch, A., Kim, D., Kim, S., Kokubo, Y., Kuate Defo, B., Kucuk Bicer, B., Kumar, G. A., Larsson, A., Leasher, J. L., Leung, R., Li, Y., Lipshultz, S. E., Lopez, A. D., Lotufo, P. A., Lunevicius, R., Lyons, R. A., Majdan, M., Malekzadeh, R., Mashal, T., Mason-Jones, A. J., Melaku, Y. A., Memish, Z. A., Mendoza, W., Miller, T. R., Mock, C. N., Murray, J., Nolte, S., Oh, I. H., Olusanya, B. O., Ortblad, K. F., Park, E. K., Paternina Caicedo, A. J., Patten, S. B., Patton, G. C., Pereira, D. M., Perico, N., Piel, F. B., Polinder, S., Popova, S., Pourmalek, F., Quistberg, D. A., Remuzzi, G., Rodriguez, A., Rojas-Rueda, D., Rothenbacher, D., Rothstein, D. H., Sanabria, J., Santos, I. S., Schwebel, D. C., Sepanlou, S. G., Shaheen, A., Shiri, R., Shiue, I., Skirbekk, V., Sliwa, K., Sreeramareddy, C. T., Stein, D. J., Steiner, T. J., Stovner, L. J., Sykes, B. L., Tabb, K. M., Terkawi, A. S., Thomson, A. J., Thorne-Lyman, A. L., Towbin, J. A., Ukwaja, K. N., Vasankari, T., Venketasubramanian, N., Vlassov, V. V., Vollset, S. E., Weiderpass, E., Weintraub, R. G., Werdecker, A., Wilkinson, J. D., Woldeyohannes, S. M., Wolfe, C. D., Yano, Y., Yip, P., Yonemoto, N., Yoon, S. J., Younis, M. Z., Yu, C., El Sayed Zaki, M., Naghavi, M., Murray, C. J., \& Vos, T. (2016). Global and national burden of diseases and injuries among children and adolescents between 1990 and 2013: Findings from the global burden of disease 2013 study. JAMA Pediatrics, 170(3), 267-287. doi:10.1001/ jamapediatrics.2015.4276

Hammen, C. (2005). Stress and depression. Annual Review of Clinical Psychology, 1(1), 293-319. doi:10.1146/annurev. clinpsy.1.102803.143938

Horgan, A., Kelly, P., Goodwin, J., \& Behan, L. (2018). Depressive symptoms and suicidal ideation among Irish undergraduate college students. Issues in Mental Health Nursing, 1-10. Advance online publication. doi:10.1080/01612840.2017. 1422199

Jin, X., Chang, X., \& Ma, D. (2013). Depression of junior high school students. China Journal of Health Psychology, 21(4), 587-589. doi:10.13342/j.cnki.cjhp.2013.04.012

Jones, J. E., Hermann, B. P., Woodard, J. L., Barry, J. J., Gilliam, F., Kanner, A. M., \& Meador, K. J. (2005). Screening for major depression in epilepsy with common self-report depression inventories. Epilepsia, 46(5), 731-735. doi:10. 1111/j.1528-1167.2005.49704.x

Kardefelt-Winther, D. (2014). Problematizing excessive online gaming and its psychological predictors. Computers in Human Behavior, 31, 118-122. doi:10.1016/j.chb.2013.10.017 
Kim, J., \& Haridakis, P. M. (2009). The role of Internet user characteristics and motives in explaining three dimensions of Internet addiction. Journal of Computer-Mediated Communication, 14(4), 988-1015. doi:10.1111/j.1083-6101.2009. 01478.x

King, D. L., Delfabbro, P. H., Doh, Y. Y., Wu, A. M., Kuss, D. J., Pallesen, S., Mentzoni, R., Carragher, N., \& Sakuma, H. (2018). Policy and prevention approaches for disordered and hazardous gaming and Internet use: An international perspective. Prevention Science, 19(2), 233-249. doi:10.1007/s11121017-0813-1

Ko, C. H., Wang, P. W., Liu, T. L., Yen, C. F., Chen, C. S., \& Yen, J. Y. (2015). Bidirectional associations between family factors and Internet addiction among adolescents in a prospective investigation. Psychiatry and Clinical Neurosciences, 69(4), 192-200. doi:10.1111/pen.12204

Ko, C. H., Yen, J. Y., Chen, C. C., Chen, S. H., Wu, K., \& Yen, C. F. (2006). Tridimensional personality of adolescents with Internet addiction and substance use experience. The Canadian Journal of Psychiatry, 51(14), 887-894. doi:10.1177/ 070674370605101404

Ko, C. H., Yen, J. Y., Chen, C. S., Yeh, Y. C., \& Yen, C. F. (2009). Predictive values of psychiatric symptoms for Internet addiction in adolescents: A 2-year prospective study. Archives of Pediatrics and Adolescent Medicine, 163(10), 937-943. doi:10.1001/archpediatrics.2009.159

Ko, C. H., Yen, J. Y., Liu, S. C., Huang, C. F., \& Yen, C. F. (2009). The associations between aggressive behaviors and Internet addiction and online activities in adolescents. Journal of Adolescent Health, 44(6), 598-605. doi:10.1016/j.jadohealth. 2008.11.011

Ko, C. H., Yen, J. Y., Yen, C. F., Chen, C. C., Yen, C. N., \& Chen, S. H. (2005). Screening for Internet addiction: An empirical study on cut-off points for the Chen Internet Addiction Scale. The Kaohsiung Journal of Medical Sciences, 21(12), 545-551. doi:10.1016/S1607-551X(09)70206-2

Lam, L. T. (2015). Parental mental health and Internet addiction in adolescents. Addictive Behaviors, 42, 20-23. doi:10.1016/j. addbeh.2014.10.033

Lam, L. T., \& Peng, Z. W. (2010). Effect of pathological use of the Internet on adolescent mental health: A prospective study. Archives of Pediatrics and Adolescent Medicine, 164(10), 901-906. doi:10.1001/archpediatrics.2010.159

Lam, T. H., Stewart, S. M., Ho, S. Y., Lai, M. K., Mak, K. H., Chau, K. V., Rao, U., \& Salili, F. (2005). Depressive symptoms and smoking among Hong Kong Chinese adolescents. Addiction, 100(7), 1003-1011. doi:10.1111/j.1360-0443.2005. 01092.x

Lau, J. T. F., Gross, D. L., Wu, A. M. S., Cheng, K. M., \& Lau, M. M. C. (2017). Incidence and predictive factors of Internet addiction among Chinese secondary school students in Hong Kong: A longitudinal study. Social Psychiatry and Psychiatric Epidemiology, 52(6), 657-667. doi:10.1007/s00127017-1356-2

Leung, C., \& To, H. (2009). The relationship between stress and bullying among secondary school students. New Horizons in Education, 57(1), 33-42.

Lewinsohn, P. M., Rohde, P., \& Seeley, J. R. (1994). Psychosocial risk factors for future adolescent suicide attempts. Journal of Consulting and Clinical Psychology, 62(2), 297-305. doi:10. 1037/0022-006X.62.2.297
Li, D., Liau, A., \& Khoo, A. (2011). Examining the influence of actual-ideal self-discrepancies, depression, and escapism, on pathological gaming among massively multiplayer online adolescent gamers. Cyberpsychology, Behavior, and Social Networking, 14(9), 535-539. doi:10.1089/cyber.2010.0463

Li, H. C. W., Chan, S. L. P., Chung, O. K. J., \& Chui, M. L. M. (2010). Relationships among mental health, self-esteem and physical health in Chinese adolescents: An exploratory study. Journal of Health Psychology, 15(1), 96-106. doi:10.1177/ 1359105309342601

Li, W., Garland, E. L., \& Howard, M. O. (2014). Family factors in Internet addiction among Chinese youth: A review of Englishand Chinese-language studies. Computers in Human Behavior, 31, 393-411. doi:10.1016/j.chb.2013.11.004

Li, Z., \& Hicks, M. H. R. (2010). The CES-D in Chinese American women: Construct validity, diagnostic validity for major depression, and cultural response bias. Psychiatry Research, 175(3), 227-232. doi:10.1016/j.psychres.2009.03.007

Lin, H. C., Tang, T. C., Yen, J. Y., Ko, C. H., Huang, C. F., Liu, S. C., \& Yen, C. F. (2008). Depression and its association with self-esteem, family, peer and school factors in a population of 9586 adolescents in southern Taiwan. Psychiatry and Clinical Neurosciences, 62(4), 412-420. doi:10.1111/j.14401819.2008.01820.x

Liu, P., Hong, W., \& Niu, L. (2012). A current situation survey and influence factors of adolescent depression in suburban district. Chinese Journal of Clinical Psychology, 20(5), 668-669. doi:10.16128/j.cnki.1005-3611.2012.05.038

Mak, K., Lai, C., Ko, C., Chou, C., Kim, D., Watanabe, H., \& Ho, R. C. M. (2014). Psychometric properties of the Revised Chen Internet Addiction Scale (CIAS-R) in Chinese adolescents. Journal of Abnormal Child Psychology, 42(7), 1237-1245. doi:10.1007/s10802-014-9851-3

Mak, K. K., Lai, C. M., Watanabe, H., Kim, D. I., Bahar, N., Ramos, M., Young, K. S., Ho, R. C., Aum, N. R., \& Cheng, C. (2014). Epidemiology of Internet behaviors and addiction among adolescents in six Asian countries. Cyberpsychology, Behavior, and Social Networking, 17(11), 720-728. doi:10. 1089/cyber.2014.0139

Maraz, A., Király, O., \& Demetrovics, Z. (2015). Commentary on: Are we overpathologizing everyday life? A tenable blueprint for behavioral addiction research. The diagnostic pitfalls of surveys: If you score positive on a test of addiction, you still have a good chance not to be addicted. Journal of Behavioral Addictions, 4(3), 151-154. doi:10.1556/2006.4.2015.026

Montag, C., Bey, K., Sha, P., Li, M., Chen, Y. F., Liu, W. Y., Zhu, Y. K., Li, C. B., Markett, S., Keiper, J., \& Reuter, M. (2015). Is it meaningful to distinguish between generalized and specific Internet addiction? Evidence from a cross-cultural study from Germany, Sweden, Taiwan and China. Asia-Pacific Psychiatry, 7(1), 20-26. doi:10.1111/appy.12122

Nguyen, D. T., Dedding, C., Pham, T. T., \& Bunders, J. (2013). Perspectives of pupils, parents, and teachers on mental health problems among Vietnamese secondary school pupils. BMC Public Health, 13(1), 1046. doi:10.1186/1471-245813-1046

O’Connor, M., Hawkins, M. T., Toumbourou, J. W., Sanson, A., Letcher, P., \& Olsson, C. A. (2011). The relationship between social capital and depression during the transition to adulthood. Australian Journal of Psychology, 63(1), 26-35. doi:10.1111/ j.1742-9536.2011.00004.x 
Park, S. K., Kim, J. Y., \& Cho, C. B. (2008). Prevalence of Internet addiction and correlations with family factors among South Korean adolescents. Adolescence, 43, 895-909.

Radloff, L. S. (1977). The CES-D scale: A Self-Report Depression Scale for research in the general population. Applied Psychological Measurement, 1(3), 385-401. doi:10.1177/ 014662167700100306

Radloff, L. S. (1991). The use of the Center for Epidemiologic Studies Depression Scale in adolescents and young adults. Journal of Youth and Adolescence, 20(2), 149-166. doi:10. 1007/BF01537606

Rierdan, J., Koff, E., \& Stubbs, M. L. (1989). A longitudinal analysis of body image as a predictor of the onset and persistence of adolescent girls' depression. The Journal of Early Adolescence, 9(4), 454-466. doi:10.1177/027243168 9094006

Roberts, R. E., Andrews, J. A., Lewinsohn, P. M., \& Hops, H. (1990). Assessment of depression in adolescents using the Center for Epidemiologic Studies Depression Scale. Psychological Assessment, 2(2), 122-128. doi:10.1037/1040-3590.2. 2.122

Rodrigo, C., Welgama, S., Gurusinghe, J., Wijeratne, T., Jayananda, G., \& Rajapakse, S. (2010). Symptoms of anxiety and depression in adolescent students; a perspective from Sri Lanka. Child and Adolescent Psychiatry and Mental Health, 4(1), 10. doi:10.1186/1753-2000-4-10

Ryan, T., Chester, A., Reece, J., \& Xenos, S. (2014). The uses and abuses of Facebook: A review of Facebook addiction. Journal of Behavioral Addictions, 3(3), 133-148. doi:10.1556/JBA. 3.2014 .016

Schoenbach, V. J., Kaplan, B. H., Wagner, E. H., Grimson, R. C., \& Miller, F. T. (1983). Prevalence of self-reported depressive symptoms in young adolescents. American Journal of Public Health, 73(11), 1281-1287. doi:10.2105/AJPH.73.11.1281

Sheeber, L., Hops, H., Alpert, A., Davis, B., \& Andrews, J. (1997). Family support and conflict: Prospective relations to adolescent depression. Journal of Abnormal Child Psychology, 25(4), 333-344. doi:10.1023/A:1025768504415

Sin, N. L., \& Lyubomirsky, S. (2009). Enhancing well-being and alleviating depressive symptoms with positive psychology interventions: A practice-friendly meta-analysis. Journal of Clinical Psychology, 65(5), 467-487. doi:10.1002/jclp.20593

Stahl, D., Sum, C. F., Lum, S. S., Liow, P. H., Chan, Y. H., Verma, S., Chua, H. C., \& Chong, S. A. (2008). Screening for depressive symptoms: Validation of the Center for Epidemiologic Studies Depression Scale (CES-D) in a multiethnic group of patients with diabetes in Singapore. Diabetes Care, 31(6), 1118-1119. doi:10.2337/dc07-2019

Starcevic, V. (2013). Is Internet addiction a useful concept? Australian and New Zealand Journal of Psychiatry, 47(1), 16-19. doi:10.1177/0004867412461693

Suh, S., Kim, H., Yang, H. C., Cho, E. R., Lee, S. K., \& Shin, C. (2013). Longitudinal course of depression scores with and without insomnia in non-depressed individuals: A 6-year follow-up longitudinal study in a Korean cohort. Sleep, 36(3), 369-376. doi:10.5665/sleep.2452

Supartini, A., Oishi, T., \& Yagi, N. (2017). Sex differences in the relationship between sleep behavior, fish consumption, and depressive symptoms in the general population of South Korea.
International Journal of Environmental Research and Public Health, 14(7), 789. doi:10.3390/ijerph14070789

Tamura, H., Nishida, T., Tsuji, A., \& Sakakibara, H. (2017). Association between excessive use of mobile phone and insomnia and depression among Japanese adolescents. International Journal of Environmental Research and Public Health, 14(7), 701. doi:10.3390/ijerph14070701

Tang, J., Yu, Y., Du, Y., Ma, Y., Zhang, D., \& Wang, J. (2014). Prevalence of Internet addiction and its association with stressful life events and psychological symptoms among adolescent Internet users. Addictive Behaviors, 39(3), 744-747. doi:10. 1016/j.addbeh.2013.12.010

Tillmann, T., Pikhart, H., Peasey, A., Kubinova, R., Pajak, A., Tamosiunas, A., Malyutina, S., Steptoe, A., Kivimäki, M., Marmot, M., \& Bobak, M. (2017). Psychosocial and socioeconomic determinants of cardiovascular mortality in Eastern Europe: A multicentre prospective cohort study. PLoS Medicine, 14(12), e1002459. doi:10.1371/journal.pmed.1002459

van den Eijnden, R. J., Meerkerk, G. J., Vermulst, A. A., Spijkerman, R., \& Engels, R. C. (2008). Online communication, compulsive Internet use, and psychosocial well-being among adolescents: A longitudinal study. Developmental Psychology, 44(3), 655-665. doi:10.1037/0012-1649.44. 3.655

Vondráčková, P., \& Gabrhelík, R. (2016). Prevention of Internet addiction: A systematic review. Journal of Behavioral Addictions, 5(4), 568-579. doi:10.1556/2006.5.2016.085

Weissman, M. M., Orvaschel, H., \& Padian, N. (1980). Children's symptom and social functioning self-report scales comparison of mothers' and children's reports. The Journal of Nervous and Mental Disease, 168(12), 736-740. doi:10.1097/00005053198012000-00005

Weissman, M. M., Sholomskas, D., Pottenger, M., Prusoff, B. A., \& Locke, B. Z. (1977). Assessing depressive symptoms in five psychiatric populations: A validation study. American Journal of Epidemiology, 106(3), 203-214. doi:10.1093/oxfordjournals.aje.a112455

Wong, J. P., Stewart, S. M., Claassen, C., Lee, P. W., Rao, U., \& Lam, T. H. (2008). Repeat suicide attempts in Hong Kong community adolescents. Social Science \& Medicine, 66(2), 232-241. doi:10.1016/j.socscimed.2007.08.031

Wu, A. M. S., Chen, J. H., Tong, K. K., Yu, S., \& Lau, J. T. F. (2018). Prevalence and associated factors of Internet gaming disorder among community dwelling adults in Macao, China. Journal of Behavioral Addictions, 7(1), 62-69. doi:10.1556/ 2006.7.2018.12

Yan, W., Li, Y., \& Sui, N. (2014). The relationship between recent stressful life events, personality traits, perceived family functioning and Internet addiction among college students. Stress and Health, 30(1), 3-11. doi:10.1002/smi.2490

Yang, H. J., Soong, W. T., Kuo, P. H., Chang, H. L., \& Chen, W. J. (2004). Using the CES-D in a two-phase survey for depressive disorders among nonreferred adolescents in Taipei: A stratum-specific likelihood ratio analysis. Journal of Affective Disorders, 82(3), 419-430. doi:10.1016/j. jad.2004.04.008

Yang, L., Jia, C. X., \& Qin, P. (2015). Reliability and validity of the Center for Epidemiologic Studies Depression Scale (CES-D) among suicide attempters and comparison residents 
in rural China. BMC Psychiatry, 15(1), 76. doi:10.1186/ s12888-015-0458-1

Yang, S. C., \& Tung, C. J. (2007). Comparison of Internet addicts and non-addicts in Taiwanese high school. Computers in Human Behavior, 23(1), 79-96. doi:10.1016/j.chb.2004. 03.037

Yen, C. F., Ko, C. H., Yen, J. Y., Chang, Y. P., \& Cheng, C. P. (2009). Multi- dimensional discriminative factors for Internet addiction among adolescents regarding gender and age.
Psychiatry and Clinical Neurosciences, 63(3), 357-364. doi:10.1111/j.1440-1819.2009.01969.x

Yen, J. Y., Yen, C. F., Chen, C. C., Chen, S. H., \& Ko, C. H. (2007). Family factors of Internet addiction and substance use experience in Taiwanese adolescents. CyberPsychology \& Behavior, 10(3), 323-329. doi:10.1089/cpb.2006.9948

Young, K. S. (2004). Internet addiction - A new clinical phenomenon and its consequences. American Behavioral Scientist, 48(4), 402-415. doi:10.1177/0002764204270278 